\title{
A case study on the perspectives of University of Santo Tomas pharmacy professors on the influence of online classes in pharmacy education
}

\author{
Heidus Renzo G. Palomares, Precious Pauline M. Pantoja, Kristefanie E. Pascua, Alyanna Lou D. Pfleider, \\ Andrea Nicole T. Polintan (D, Rania Mariel D. Reyes, Ann Patrizia A. Rivera, Rhona P. Ramos \\ Faculty of Pharmacy, University of Santo Tomas, Manila, Philippines
}

\author{
Keywords \\ COVID-19 \\ Online learning \\ Perspective \\ Pharmacy education

\section{Correspondence} \\ Andrea Nicole T. Polintan \\ Department of Pharmacy \\ Faculty of Pharmacy \\ University of Santo Tomas \\ Manila \\ Philippines \\ andreanicole.polintan.pharma@ust.edu.ph
}

\begin{abstract}
Objective: The COVID-19 pandemic has shifted the academic environment into distance learning. In the University of Santo Tomas (UST) Faculty of Pharmacy, an Enriched Virtual Mode of Learning was used to deliver the online teaching and learning process. This study aimed to determine the influences that online learning had on the standard of pharmacy education. Methods: A qualitative case study research design was utilised and gathered the perspectives of eight UST pharmacy professors. Results: During thematic analysis, several themes were identified which were rooted in the ten key components of online learning. Conclusions: The study concluded that online learning had more negative influences than positive influences on pharmacy education. Regarding pharmacy courses, the Quality Control, Microbiology, and Public Health clusters were identified as the most difficult to teach online while the Biochemistry and Pharmacognosy clusters were the least. Recommended adjustments to improve learning outcomes focused on enhanced review methods during the course audit.
\end{abstract}

\section{Introduction}

In the year 2020, a pandemic brought about by the virus scientifically known as SARS-CoV-2 caused educational institutions all over the world to cease all face-to-face operations in order to prevent the further spread of the disease. To cope with the changing landscape of education in the Philippines, other innovative learning methods were explored to facilitate teaching and learning amidst the pandemic (CHED Memorandum Order No. 4, 2020). At the University of Santo Tomas (UST), the Enhanced Virtual Mode (EVM), as one part of the Institutional Continuity Plan During Extended and Post-Enhanced Community Quarantine (2020), was utilised. This involved a combination of synchronous and asynchronous online classes and activities using the university's learning management system, Blackboard, through the UST Cloud Campus. Synchronous methods involve real-time teaching and learning with instantaneous feedback, while asynchronous methods allow students to access the course content at their own time and pace (Watts, 2016). With the implementation of online learning, the effectiveness of online pharmacy education in achieving necessary learning outcomes varied per student as each student dealt with different learning factors and barriers.

\section{Theoretical framework}

A new model of effective online learning is presented in Figure 1. The model was constructed in combination with three well-known theoretical frameworks of online learning: (a) Self-regulated learning theory, (b) Theory of transactional distance, and (c) Collaborative control. This framework includes ten key internal and external components applicable to the research phenomenon observed. 


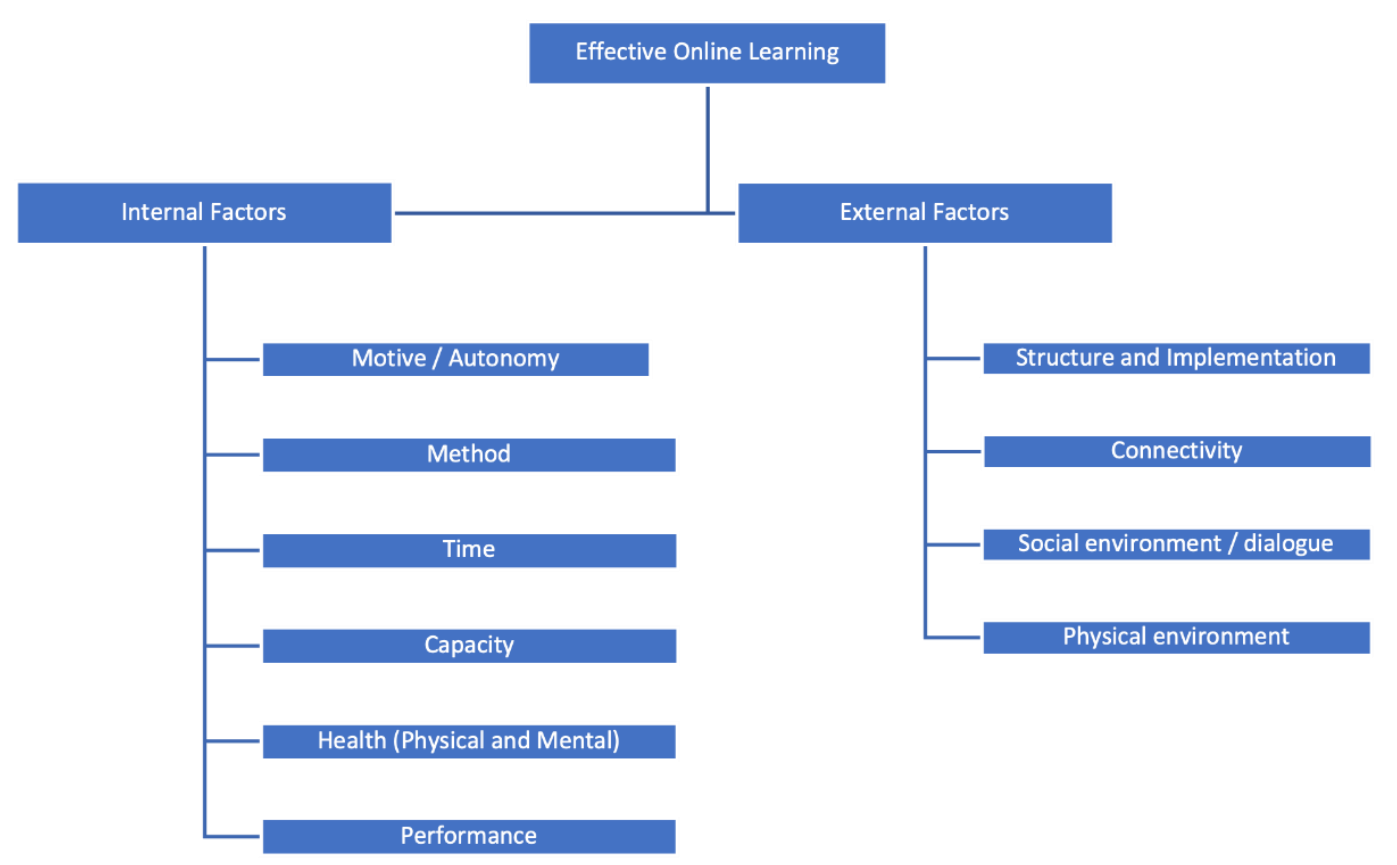

Figure 1: Effective online learning: A new framework

The researchers hypothesised that the presence or absence, availability or unavailability, attainment or inadequacy of the key components of online learning during the pandemic would contribute either positively or negatively towards the achievement of necessary learning outcomes in pharmacy education.

\section{Objective}

The study aimed to identify the influences of online learning on pharmacy education based on the perspectives of UST pharmacy professors.

\section{Methods}

\section{Study design and participants}

The study utilised a qualitative case study research design. The researchers used a convenience sampling technique with the following criteria for participants: UST pharmacy professors teaching pharmacy board exam subjects with at least three years of full time and/or part-time teaching experience in the university. Priority participants for the study were the pharmacy course auditors. They are professors who conduct the board exam review for students during the pharmacy course audit. Pharmacy course instructors were excluded from the study if they did not fit the inclusion criteria, and only had teaching experience in the old or previous Bachelor of Pharmacy curriculum in the Philippines. The researchers obtained consent from all eight participants of the study.

\section{Data collection}

One-on-one online audio-visual interviews were conducted with the participants. A semi-structured interview guide consisting of seven open-ended and ranking questions was used to properly facilitate the interview (Table I). Questions were initially adapted from the study of Khalil and colleagues in 2020, which focused on online learning amidst the COVID-19 pandemic. The instrument was modified substantially to fit the study's objectives. The researchers conducted a pilot study which substantiated the questionnaire's capacity to prompt meaningful responses that contributed to the attainment of research objectives.

Signed consent was obtained from all participants prior to the scheduled interview. Participants were assured that data privacy was carried out for the entire duration of the study.

Although a larger sample size would have revealed additional insights, the researchers were satisfied that the perspectives gathered were sufficient enough to achieve data saturation due to repetition of ideas. The duration of the interview ranged from about 20 to 30 minutes. Interviews were recorded as videos and transcribed by the researchers in a word format. To protect confidentiality, participants were identified as respondents in all notes and transcripts. Interviews were conducted in April 2021, which was near the end of the second academic term. 
Table I: Interview questions

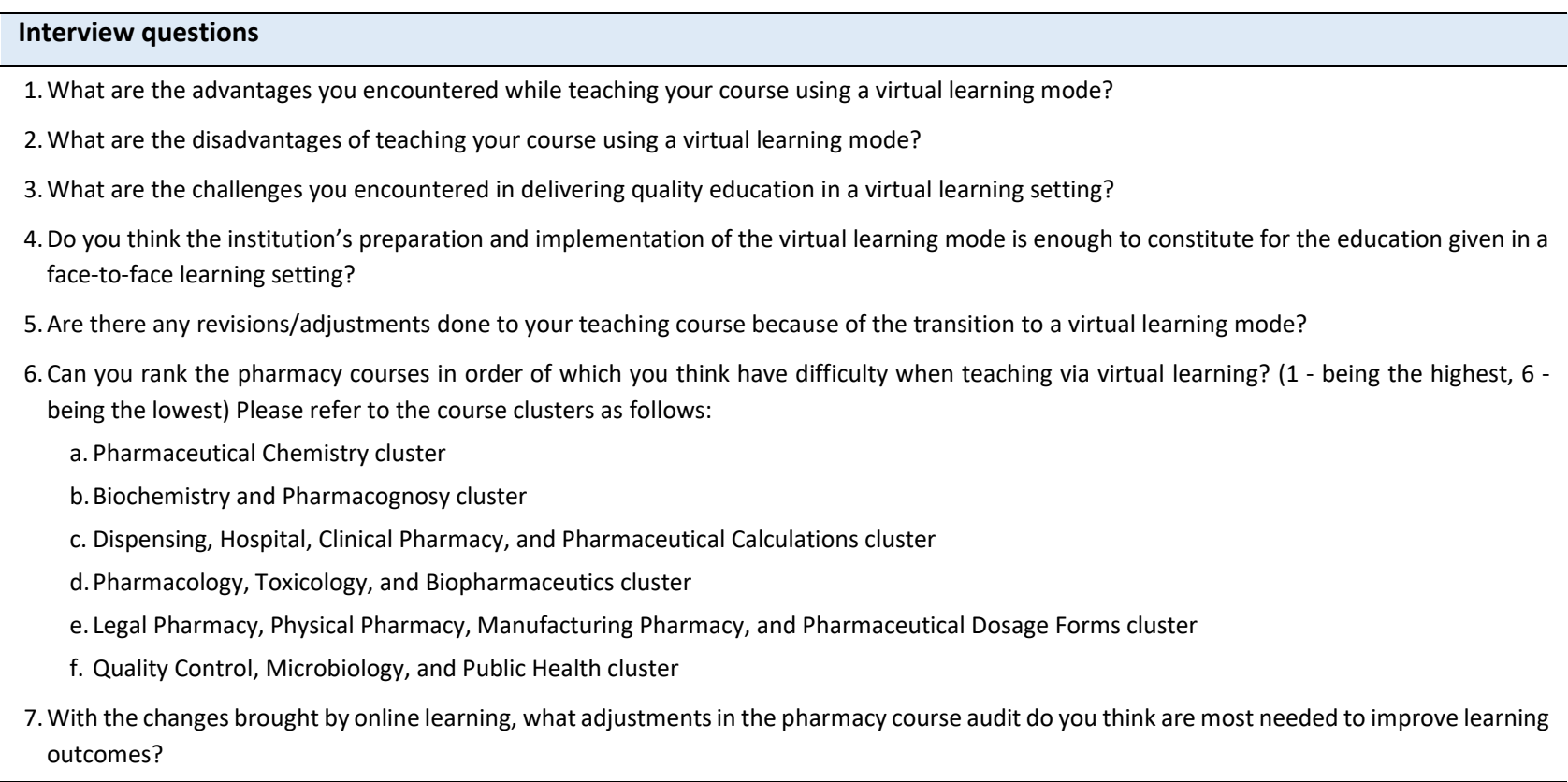

\section{Data analysis}

After the collection and transcription of data, a thematic analysis was conducted by the researchers. The researchers established pertinent codes per transcribed material using a deductive approach to determine which among the ten key components of online learning, as stated in the authors' theoretical framework, were elicited from the perspectives of the participants. From here, emerging themes were identified, which were linked together into cohesive themes per research question to meet the study's objectives.

\section{Ethics approval}

The Faculty of Pharmacy's research ethics committee reviewed and approved the dissertation proposal prior to the conduction of a proper interview. In line with this, the committee assigned this study a protocol code (FOP-ERC-2021- 01-117).

\section{Results}

The themes established were categorised according to the questions asked. All themes were consistent with the study's theoretical framework, which hypothesised that the ten key components of online learning were significant factors in the online teaching-learning experience of professors and students, as seen in Figure 2.

\section{(i) Advantages of online learning}

Based on the perspectives of pharmacy professors, the advantages of online pharmacy learning highlighted three themes, including a) Learning accessibility and flexibility, b) Convenience and preservation of economic resources, and c) Engagement.

\section{(i.a.) Learning accessibility and flexibility}

Almost all respondents addressed the learning accessibility and flexibility theme that both professors and students experienced during online learning. Most of them agreed that the virtual learning mode helped with easier access to lessons and the course outline. Most of the respondents emphasised the fact that teachers could just post their course materials, and the students could then access those materials anytime, anywhere. Furthermore, the respondents expressed that supplementary learning materials were readily available and easily accessible online for both teachers and students:

"Anytime, anywhere you can conduct the courses. And of course, another one would be the availability of our resources anytime as well and anywhere. And in this way even though we are away from each other you can connect with the students as what we are doing now right. Even though I am in the province, you're in the city, you are in the provinces as well but still we can connect to each one. I think that would be one of the advantages especially if, for example, students want or need certain references or resources about their subjects or courses, it is readily available online." 


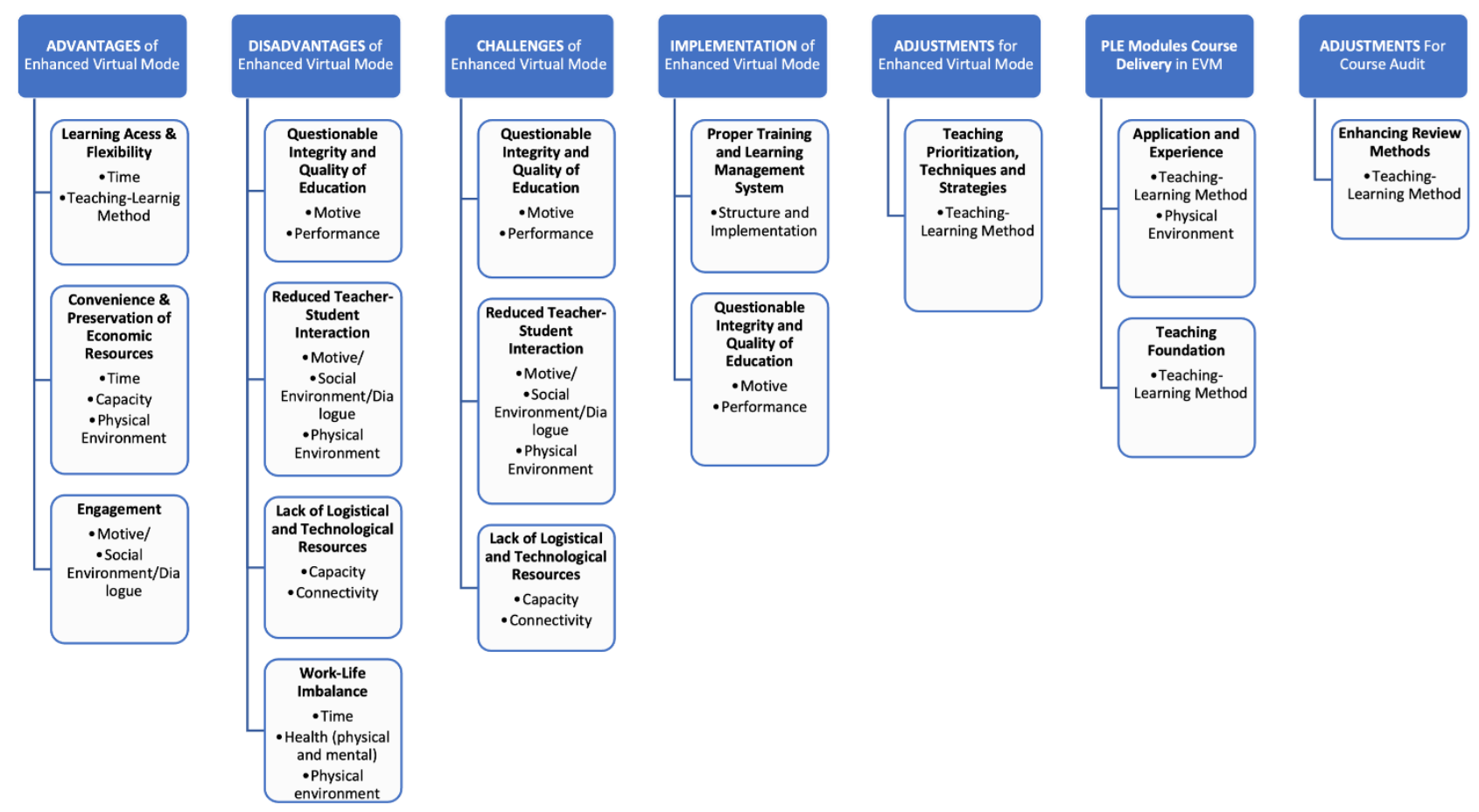

Figure 2: Themes and corresponding key components

\section{(i.b.) Convenience and preservation of economic resources}

Another theme discussed by the professors was the convenience and preservation of economic resources that online learning brought to both students and teachers. One stated that they were at the comfort of their homes when teaching their students. It meant that they were comfortable working, and they had their own space:

"Consider the practical aspect, of course, the fact that [they] don't need to commute or do transport to go to school and go to classrooms. It is more convenient in terms of time because [they] can do it in their homes."

\section{(i.c.) Engagement}

The last theme that a few respondents answered for this question was with regard to engagement which included not only student-teacher interaction but also studentstudent and student-professionals interactions. These respondents stated that open communication was made easier with the use of online platforms:

"The open communication between the students and professors, so still there is what you call time limit or time frame for you to be able to communicate with your professors and at the same time not only with your professors but for your classmates, open communication with your classmates, and not only with your classmates and maybe other professionals wherein you can easily communicate through email through any means of communication because of this virtual learning mode."

\section{(ii) Disadvantages of online learning}

On the other hand, there are four emerging themes that describe the disadvantages of online learning, namely: a) Questionable integrity and quality of education, b) Reduced student-teacher interaction, c) Work-life imbalance, and d) Lack of logistical and technological resources.

\section{(ii.a) Questionable integrity and quality of education}

One of the disadvantages that the professors noticed while using the virtual learning mode was that there was questionable integrity and quality of education. In regards to integrity, the respondents believed that it was harder to assess if the students were performing tasks as instructed and if they were working individually or in groups. A respondent mentioned that the students were probably:

"doing more collaborative work with their classmates during assessments." 
This can compromise the quality of education on top of the lack of hands-on experience in the laboratory components of courses.

One respondent mentioned the problems encountered on their Blackboard software. She elaborated that:

"So far it has been decent. It's been doing what we expected it to perform for us, but there are some glitches before like there was this time last year. For example, 100-item test you have to do all those 100 items times the number of sections, that is impossible. So, those minor glitches in face-to-face it's solvable, there are a lot of things you can do anyway, but if it is online, you are at mercy of the proper functioning of your Learning Management System (LMS), even a minor glitch can carry you apart. Especially remember that time that it's exam week and there is a blue screen coming out from the Blackboard. That's also a minor [problem] if you think about it in face-to-face, but in online classes it crashes everything."

\section{(ii.b) Reduced student-teacher interaction}

Another theme highlighted by most of the respondents was the reduced student-teacher interaction which mostly stemmed from difficulty in monitoring the students during classes when cameras were turned off. One stated that this disadvantage was particularly evident in courses with computational problems. Moreover, one expressed a lack of personal touch in teaching the course, and another shared students' loss of motivation in participating in online learning in a home set-up. These were verbally conveyed as:

"[We are] having a hard time [in assessing] if the students really understood on how to compute the problems for the PhyPhar [Physical Pharmacy]. Unlike before, when you see their faces, you could easily identify if they understood or not the solution or the computation of PhyPhar. But now since it's face to face - it's online, so that, that would be my - I think that's the disadvantage also in the virtual learning mode of teaching Phyphar."

\section{(ii.c) Work-life imbalance}

Some of the respondents mentioned as well that the virtual learning mode compromised the work-life balance of the professors. One stated that students were also likely to experience a similar study-life imbalance. The respondents articulated that:

"I think a lot of teachers were, let's just say, it's not probably conscious effort, but I think there is a blurring of the fine lines that divides work or school works from the home part of your personal life. And since we are at home on a daily basis, the tendency is that teachers will just dump activities, quizzes, and will ask for projects that can be done face-toface but difficult to do online."

"The fact that if you do things at home there is no separation between your personal space and workspace, and because everyone mentions and experiences it as much, most students must have experienced that too."

\section{(ii.d) Lack of logistical and technological resources}

Some of the respondents explained that online learning resources malfunctioning (e.g. poor internet connectivity and devices) represent another disadvantage of online learning. A respondent mentioned that this applied not only to students but also to the professors:

"Because if there are times that there is interruption in the connectivity, then there is a problem between the communication and exchange of information between the students and the professors. Because if there is no electricity in the area and if their internet connection is electric dependent, then therefore the communication will be very difficult between the students and professors."

\section{(iii) Challenges of online learning}

Recurring themes were observed with regards to the challenges encountered in delivering quality education via the virtual mode, such as a) Lack of logistical and technological resources, b) Reduced student-teacher interaction, and c) Questionable integrity and quality of education

\section{(iii.a) Lack of logistical and technological resources}

A major challenge that all professors encountered while using virtual learning was the lack of logistical and technological resources, including devices and internet connectivity. They believe that both teachers and students were having a hard time adjusting. Not everyone is capable of acquiring the necessary resources for virtual education. To elaborate further, the respondents stated:

"It's very difficult to prepare a recorded lecture because you want to deliver a quality recorded lecture to students. And I think the first time that we have a recorded lecture, I'm not yet ready with things needed [in] doing a good or quality video or recorded lecture." 


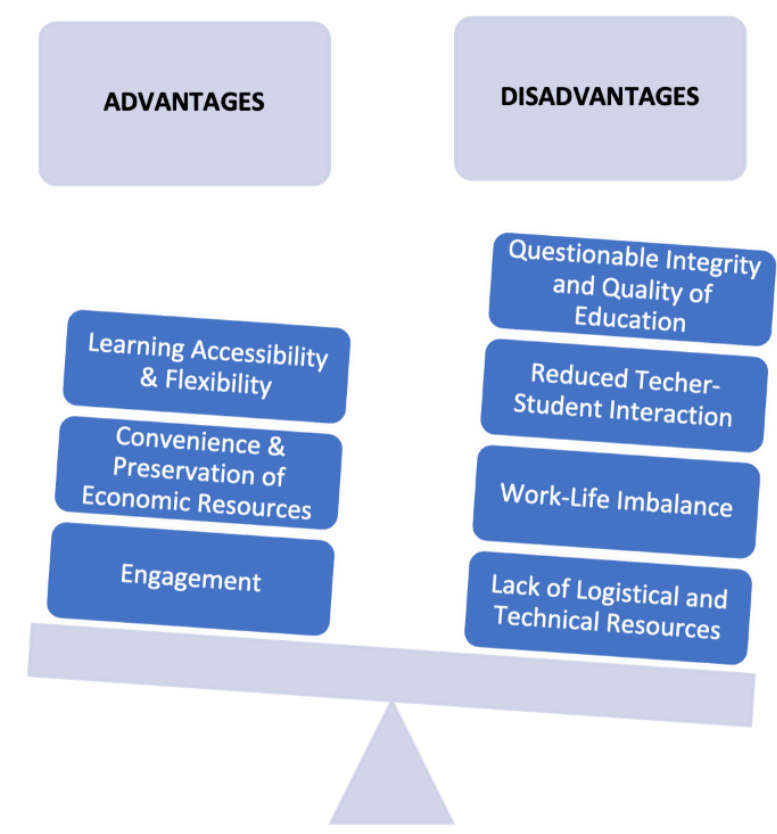

Figure 3: Advantages vs Disadvantages of online learning depicted the imbalance on the effects of virtual learning, with a greater disposition to disadvantages

Also that:

"The first ever problem I encountered was how to draw structures, chemical structures with the laptop because I had no tablet to draw then."

\section{(iii.b) Reduced student-teacher interaction}

As tackled by the professors, this theme is one of the challenges of online learning. One professor compared virtual learning and face-to-face learning interaction by mentioning that during face-to-face classes, the students were interactive or at least engaging whenever there were recitations, but during the virtual learning, the professors were not $100 \%$ sure if students were attentive during discussions. A respondent mentioned:

"[We] cannot really measure the learning of the student because we cannot monitor which of the students has a problem or absent unlike in face-toface classes we can see or we can ask the student and also one of the disadvantages is that we cannot easily monitor the students one by one."

Another stated that:

"there is no pressure if it is in an online setting. Because if it is face-to-face, some students are not listening but the fact that your teacher sees you in the same room means there is little pressure for you to at least pay attention because the person is looking at you, but in the online setting there is none. So, the attention of the student is really compromised."

\section{(iii.c) Questionable integrity and quality of education.}

Additionally, one respondent mentioned that specifically for the pharmacy course, virtual learning was not entirely applicable and should be taught in a face-to-face setting. There would have been a different experience during face-to-face classes if students could touch, smell, and experience things in a laboratory setting, which was impossible when using a virtual learning mode.

"Nothing, as in nothing, 100\%. Nothing that we do in an online or virtual mode of learning will ever constitute whatever we can provide in a face-toface learning setting, as in nothing. I mean you still get the knowledge a lot, you still learn a lot of things, but it will not be the same when you experience face-to-face setting."

\section{(iv) Implementation of online learning}

In general, most of the respondents believed that the institution was prepared for the implementation of the virtual learning mode. They believed that in preparation for the actual virtual learning mode, the institution had already provided proper training and a learning management system for the students and professors to use. One mentioned that: 
"several trainings that they are attending to. And institution is really trying their best on providing the means to improve the teaching, learning mode of delivering to students. So every day, especially during that time, it's lockdown, the professors have our training. And I think it is effective in giving us means in order to improve our online delivery of lessons to the students. And with the existing learning management of UST, I think it is very effective in giving information and providing lessons to the students."

Furthermore, another respondent stated:

"So I would say, in terms of theoretical it's good, [but] the theoretical cannot always be, you know, it doesn't always guarantee when you put it in practice".

\section{(v) Adjustments for online learning}

For this question, all respondents agreed that they adjusted their teaching prioritisation, techniques, and strategies. Most professors adjusted their course lessons to tailor-fit them to the virtual learning mode, as articulated below:

One mentioned:

"Revisions of the manuals in the laboratory. Any revisions of adjustments, again for the laboratory, [the professor] have to tailor the activities based on the materials that the students have. We cannot ask them to manufacture medications. We cannot ask them to produce or compound medications or drugs because they don't have materials on their homes. And so, we have to make sure that the activities in the laboratory are, in a way, can help them understand the topics but also doable on their own home."

Generally:

"The course content was adjusted to suit the needs of the students during the pandemic. This leads to the revisitation of the teaching-learning activities and the preparation of corresponding assessment tasks which can be used to motivate the student's learning capability in a virtual setting."

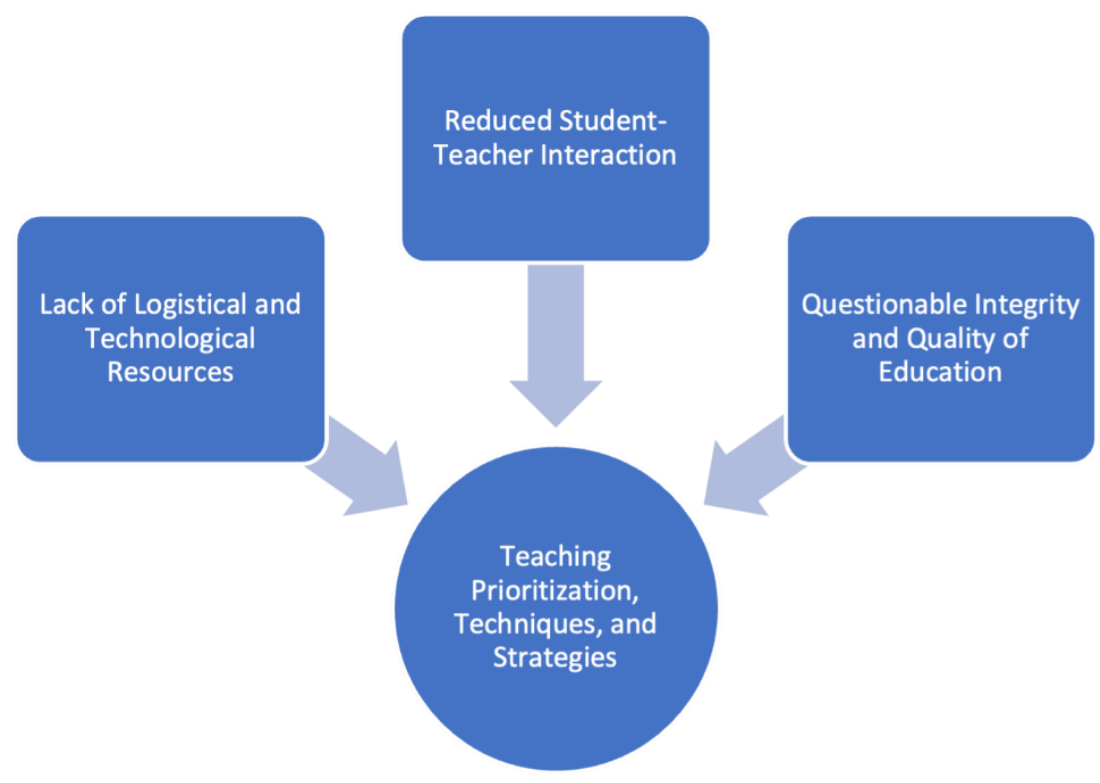

Figure 4: Illustrates that the challenges of teaching the course in an online set-up were addressed with adjustments in prioritisation, techniques, and strategies utilised by the professors in their teaching course

\section{(vi) Ranking pharmacy courses in EVM}

Table II below shows the rankings of the professors on each pharmacy cluster course. Based on the rankings, the Quality Control, Microbiology, and Public Health cluster was the hardest course with an average score of 2.38, followed by the Pharmaceutical Chemistry cluster
( $M=3.00)$, Dispensing, Hospital, Clinical Pharmacy, and Pharmaceutical Calculations cluster $(M=3.25)$, Legal Pharmacy, Physical Pharmacy, Manufacturing Pharmacy, and Pharmaceutical Dosage Forms cluster $(M=3.63)$, Pharmacology, Toxicology, and Biopharmaceutics cluster $(\mathrm{M}=4.00)$, and lastly, the Biochemistry and Pharmacognosy cluster was the easiest with an average score of 4.75 . 
Table II: Pharmacy courses ranking by clusters

\begin{tabular}{|c|c|c|c|c|c|c|c|c|c|c|}
\hline Cluster & $R 1$ & $R 2$ & $R 3$ & $R 4$ & $R 5$ & $R 6$ & $R 7$ & $R 8$ & Mean & Rank \\
\hline C1 & 3 & 4 & 4 & 5 & 2 & 1 & 3 & 2 & 3.00 & 2 \\
\hline$C 2$ & 5 & 5 & 6 & 6 & 4 & 2 & 4 & 6 & 4.75 & 6 \\
\hline C3 & 6 & 2 & 1 & 4 & 1 & 6 & 5 & 1 & 3.25 & 3 \\
\hline C4 & 4 & 1 & 5 & 3 & 6 & 3 & 6 & 4 & 4.00 & 5 \\
\hline C5 & 2 & 6 & 3 & 1 & 5 & 5 & 2 & 5 & 3.63 & 4 \\
\hline C6 & 1 & 3 & 2 & 2 & 3 & 4 & 1 & 3 & 2.38 & 1 \\
\hline
\end{tabular}

${ }^{*}$ C1: Pharmaceutical Chemistry cluster; C2: Biochemistry and Pharmacognosy cluster; C3: Dispensing, Hospital, Clinical Pharmacy, and Pharmaceutical Calculations cluster; C4: Pharmacology, Toxicology, and Biopharmaceutics cluster; C5: Legal Pharmacy, Physical Pharmacy, Manufacturing Pharmacy, and Pharmaceutical Dosage Forms cluster; C6:Quality Control, Microbiology, and Public Health cluster; R: Respondents

The professors mentioned that their rankings were based on two themes. First off, almost all respondents mainly agreed that the Application and Experience towards the course was one of their considerations. Most of them ranked the courses based on whether they required skill, laboratory experience, and practice. For them, it was easier to understand certain topics whenever you applied them to a real-life setting or scenario. There were some courses which they thought required skills, computations, and practices for them to be understood easier. As one professor mentioned:

"you can answer courses by stock knowledge [since you have applied it in real life, you remember what you did] from your laboratory experience."

Another respondent mentioned that students could practice drug testing with instrumentations, but students do not have them at home, and it would have been helpful if students could have practiced using proper instruments.
On the other hand, the respondents also believed that the foundation of how the course was being taught was also a factor in their rankings. They ranked the courses with computation as hard because it was challenging to teach computations online. As one mentioned:

"On the basis of what l've said a while ago, we could probably say now that anything with problem-solving will be hard to teach in the online setting compared to face-to-face. But for things that require more of memorization, it's less affected. Then of course, in the middle of problem-solving or math equations and pure memorization, we have this middle ground where there's a little bit of memorization and here's a little bit of analysis but not necessarily like using calculators or math. So if I'm going to put the most difficult ones, of course those would require problemsolving."

The same respondent mentioned that there were some courses that were manageable to teach in a virtual learning mode since they were based more on memorisation and analysis.
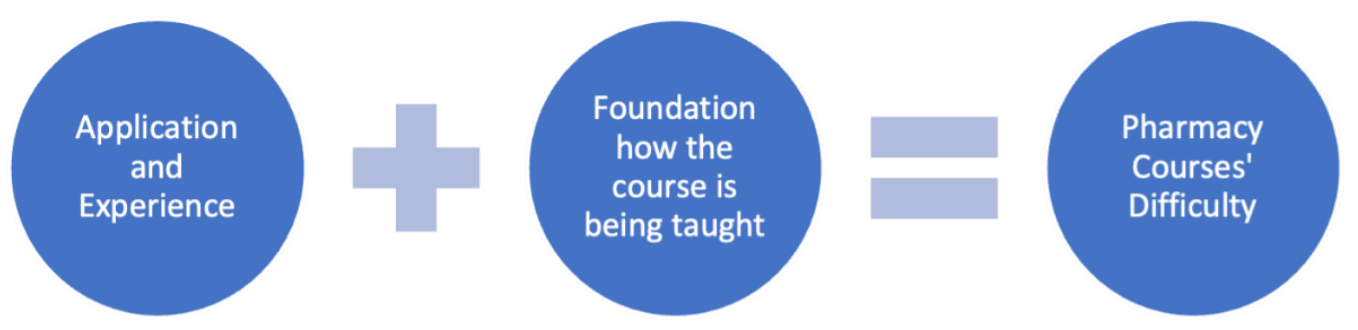

Figure 5: Formula in gauging pharmacy courses' difficulty interpreted these two themes as factors, which when put together assessed the difficulty to teach a pharmacy course via virtual learning 


\section{(vii) Adjustments for course audit}

In this section, the respondents believed that the pharmacy course audit should be adjusted by enhancing review methods to achieve the learning outcomes in pharmacy. The respondents believed that it was important that proper lesson retention and application be understood by heart. The students should be practised through testmanship of knowledge and skills. As articulated, the students:

"will be given modules to answer, and then sample questions to answer, and then rationalization of those answers. It's more on that rather than the actual lecture process or lecture with your prof. I think the rationalization will help because the board exam is most on the testmanship skills, and that's what we do in review centres - more on questions and then you are to answer them and then rationalisation."

All of these could be done by incorporating or making use of board exam questions on the practice examinations of the students. Another respondent raised as well that tips on how to review can be provided to the students. Professors should also reiterate those topics (i.e. laboratory activities) that require experiences that were not encountered by the students due to virtual learning. Professors should ensure the provision of adequate explanations and discussions that can help the students retain a recall for those topics.

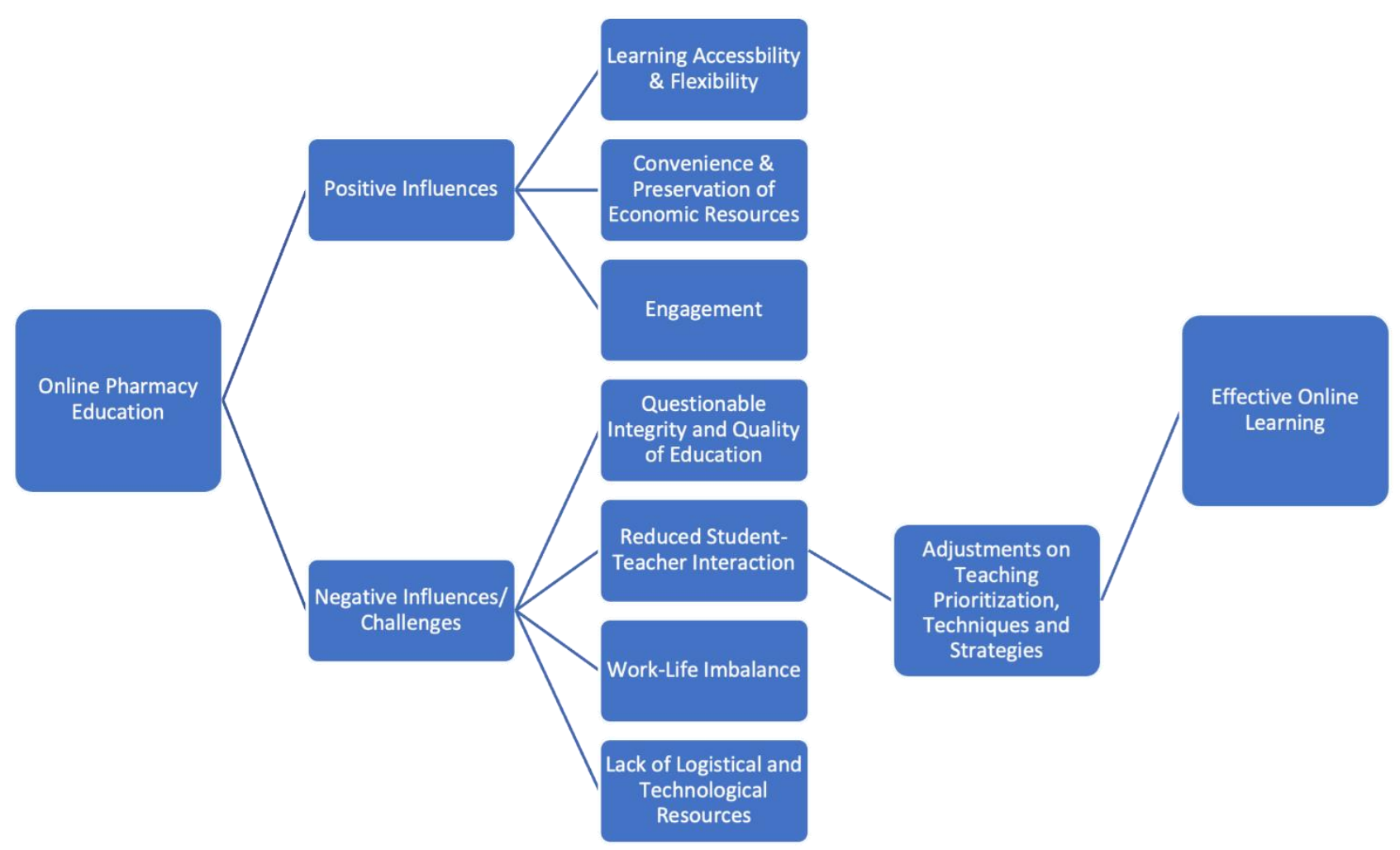

Figure 6: Thematic map of effective online learning below illustrates the relationship among the elicited themes gathered from the study, with an end goal of effective online learning

\section{Discussion}

In the UST Faculty of Pharmacy, Enhanced Virtual Mode was utilised in course delivery due to the limitations of face-to-face learning brought by the COVID-19 pandemic. Delivering an online programme required sufficient preparation for a successful institutional implementation. A Proper Training and Learning Management System was provided by the university to improve teaching methods so as to complement the virtual learning mode and to maximise online platforms and resources that were made available. Particularly, a learning management system, UST Cloud Campus - 
Blackboard, was employed, which facilitated the deployment of course materials from professors to students, provided a platform for online assessments and submission of outputs, and displayed students' performance through grade book, among its other functions. Specific course delivery guidelines for EVM were stipulated in the UST Institutional Continuity Plan during Extended and Post-ECQ (2020) and the Faculty of Pharmacy Implementing Guidelines (FOP IGs) (2020).

Despite sufficient preparation and implementation, a virtual learning environment can never constitute the education given in a face-to-face learning setting, especially in pharmacy education, wherein skills in areas such as dispensing, compounding, manufacturing, and quality control are necessary to be able to perform duties satisfactorily. Hence, there is Questionable Integrity and Quality of Education as online classes have a negative impact on skill-based learning (Kumar, 2020).

The application of an Enriched Virtual Mode of Learning has both advantages and disadvantages. Among the advantages was that Preservation of Learning Accessibility \& Flexibility was strengthened. Panigrahi and colleagues, in 2018, presented that online learning provided students with the flexibility to manage their time and learn at their own pace. Convenience and Preservation of Economic Resources refined the costeffectiveness of education during online learning since professors and students were at home thus, saving time and money (Panigrahi et al., 2018). Engagement presented the cultivation of the learner's selfregulation and self-discipline to balance his workload and achieve his learning goals with the guidance of the course structure as well as dialogue with his instructors and classmates through online learning (Moore, 1997; Andrade, 2014; Moore \& Diehl, 2019).

On the contrary, online learning has several disadvantages: Questionable Integrity and Quality of Education due to the fact that virtual learning does not provide the full experience in a learning environment, particularly clinical practices and skills development (Khalil et al., 2020). Reduced Student-Teacher Interaction was also observed in the virtual classroom, which made an assessment of students' understanding of lessons difficult. According to Gao and colleagues in 2013 and Martin \& Parker in 2014,teacher-student collaboration is a crucial component of an online class. WorkImbalance centred on the lack of separation of personal space and workspace during online class (JLL, 2020). In addition, the pandemic negatively impacted mental health and created new stressors such as constraints on physical movement, social activities, and changes in lifestyle (Son et al., 2020). Lack of Logistical and Technological Resources included power interruption and internet connection as the main concerns in the virtual set-up. Lack of resources hampered students' participation in online learning. Furthermore, acquiring electronic gadgets and stable internet connectivity was a challenge to both students and teachers (Malipot, 2020). Ultimately, the negative influences of online learning outweigh its advantages thus, presenting a negative impact on the achievement of the desired learning outcomes for the pharmacy course.

As with any profound changes in an academic setting, there were challenges encountered during the use of the virtual learning teaching mode. Firstly, there was a Lack of Logistical and Technological Resources. Teachers and students alike have varying capacities to afford resources needed and varied internet connectivity to conform to a virtual learning mode. Not everyone had sufficient access to these resources. This became a challenge for both teachers and students, especially in the presence of external factors (e.g. power interruptions, unstable internet connection) (Malipot, 2020). Reduced Student-Teacher Interaction takes into consideration the students' learning environment, which can account for students' distractions, shortened attention, and disrupted focus during class discussions. This can lead to difficulties in assessments and feelings of isolation (Abramenka, 2015). Questionable Integrity and Quality of Education presented as scepticism around collaborative work during assessments. Overdependence can negate help-seeking practice (White, 2003; Andrade, 2014). There was also underdevelopment of laboratory skills as it was an essential tool for the preparedness and application of students in real-life practice.

In addressing these challenges, the respondents made necessary adjustments to their Teaching Prioritisation, Techniques, and Strategies. Revisions on the syllabus, grading system, mode of delivery, laboratory manuals, and assessment tasks were some of the following adjustments made upon the implementation of the virtual learning mode. These were stipulated in the UST Institutional Continuity Plan during Extended and PostECQ (2020) and FOP IGs (2020). Experiments and activities were adjusted and tailored-fit to be accessible to students at home, while discussion of lectures was delivered via presentations, recorded lectures, and supplementary demonstration videos to understand the principles of the lesson.

The virtual set-up pharmacy courses varied in teaching difficulty. The respondents assessed these courses based on two criteria: Application and Experience which represented the essential hands-on application, laboratory experience, and skills development of students for particular courses; and Foundation on 
how the course is being taught wherein discussion of topics that require calculations are conducted with difficulty compared to courses which are conceptbased and rely on memorisation in a virtual learning set-up. Therefore, the final ranking of pharmacy courses in clusters based on teaching difficulty in the online setting is as follows: Quality Control, Microbiology, and Public Health, were the most difficult clusters; and Pharmaceutical Chemistry; Dispensing, Hospital, Clinical Pharmacy, and Pharmaceutical Calculations; Legal Pharmacy, Physical Pharmacy, Manufacturing Pharmacy, and Pharmaceutical Dosage Forms; Pharmacology, Toxicology, and Biopharmaceutics; and finally Biochemistry and Pharmacognosy were the least difficult clusters.

Consequently, adjustments in Course Audit were deemed necessary, particularly in Enhancing Review Methods. Appropriate assessment helps students to learn better for future competence (Hart et al., 2019). Thus, diagnostic tests, rationalising answers from assessments, and mock board exams were recommended. Students' preparation can also be significantly improved by practising self-discipline and testmanship (Harris et al., 2019).

Ultimately, the study elicited themes that addressed the research objectives, grounded on the Effective Online Learning framework. All ten key components were correlated with the emerging themes, with the Teaching-Learning Method being most associated. This translated to the changes and adjustments made in both teaching and learning to address the challenges experienced in order to maximise the positive influences and to address and minimise the negative impact of virtual learning in pharmacy education.

This study has its limitations. The study focused solely on Philippine pharmacy education, a quantitative assessment was not conducted, and the study was exclusive to UST Pharmacy professors only.

\section{Conclusion}

The study demonstrated that online learning in pharmacy education had more negative influences than positive influences. The biggest disadvantages of online learning were that there was questionable integrity and questionable quality of education due to the insufficient hands-on experiences and skills development of students; thus, corresponding adjustments were made in terms of teaching methods and strategies to achieve learning outcomes. In terms of pharmacy courses, the Quality Control, Microbiology, and Public Health clusters were identified as the most difficult to teach online and the
Biochemistry and Pharmacognosy clusters were the least, thus recommended adjustments focused on review methods during the course audit. Therefore, this study gathered new insights that can be useful tools in the achievement of desired learning outcomes in pharmacy education, particularly in a full-virtual academic setting.

\section{References}

Abramenka, V. (2015). Students' Motivations and Barriers to Online Education. Masters Theses. 766. Available at: https://scholarworks.gvsu.edu/theses/776

Andrade, M. S. (2014). Effective eLearning and eTeaching A Theoretical Model. https://doi.org/10.5772/60578

Burgess, S., \& Sievertsen, H. (2020). The impact of COVID-19 on education. Available at:

https://voxeu.org/article/impact-covid-19-education

Castillo, J. (2020). PCI Hub LMS: Preparing Filipino Students for E-Learning. Manila Bulletin

Commission on Higher Education Memorandum Order 4 otherwise known as Guidelines on the Implementation of Flexible Learning. (2020). Available at: https://ched.gov.ph/wp-content/uploads/CMO-No.-4-s.2020-Guidelines-on-the-Implementation-of-FlexibleLearning.pdf

Faculty of Pharmacy Implementing Guidelines (FOP IGs) on Enhanced Virtual Mode (EVM) Course of Delivery for AY 2020-2021. (2020, July 31). Available at: https://www.facebook.com/USTFPSC/posts/329250955414 9303

Gao, F., Zhang, T., \& Franklin, T. (2013). Designing asynchronous online discussion environments: Recent progress and possible future directions. British Journal of Educational Technology, 44(3), 469-483.

https://doi.org/10.1111/j.1467-8535.2012.01330.x

Harris, L., Harrison, D., McNally, D., \& Ford, C. (2019). Academic Integrity in an Online Culture: Do McCabe's Findings Hold True for Online, Adult Learners? Journal of Academic Ethics, 1-16. https://doi.org/10.1007/s10805019-09335-3

Hart, C. M. D., Berger, D., Jacob, B., Loeb, S., \& Hill, M. (2019). Online Learning, Offline Outcomes: Online Course Taking and High School Student Performance. AERA Open, 5(1), https://doi.org/10.1177/2332858419832852

Khalil, R., Mansour, A.E., Fadda, W.A. et al. (2020). The sudden transition to synchronized online learning during the COVID-19 pandemic in Saudi Arabia: a qualitative study exploring medical students' perspectives. BMC Med Educ 20, 285. https://doi.org/10.1186/s12909-020-02208-z

Kumar, P. (2020). Reference Based Study on Impact of Covid-19 On Education Systems. International Journal of Innovative Technology and Research. Available at: https://core.ac.uk/download/pdf/327105065.pdf 
Malipot, M. H. (2020). Lack of resources 'biggest challenge' for parents, students, teachers. Available at: https://mb.com.ph/2020/08/07/lack-of-resources-biggestchallenge-for-parents-students-teachers/

Malipot, M. H. (2020). Internet connection problems beyond our control - DepEd. Available at: https://mb.com.ph/2020/10/06/internet-connectionproblems-beyond-our-control-deped/

Martin, F., \& Parker, M. A. (2014). Use of synchronous virtual classrooms: Why, who and how? Journal of Online Learning and Teaching, 10(2), 192

Moore, M. (1997). Theory of Transactional Distance. In Keegan, D. (1997). (Ed.). Theoretical Principles of Distance Education. Routledge, pp. 22-38

Moore, M. (Ed.), Diehl, W. (Ed.). (2019). Handbook of Distance Education. New York: Routledge, https://doi.org/10.4324/9781315296135

Panigrahi, R., Srivastava, P., \& Sharma, D. (2018). Online learning: Adoption, continuance, and learning outcome-A review of literature. International Journal of Information Management.

https://doi.org/10.1016/j.ijinfomgt.2018.05.005

UST Faculty Of Pharmacy. (2021). Implementing Guidelines For Course Audit During COVID-19 Pandemic.

UST Institutional Continuity Plan during Extended and PostECQ (2020, April 8). Available at:

http://www.ust.edu.ph/wp-

content/uploads/2020/06/Institutional-Continuity-Planduring-Extended-and-Post-ECQ.pdf

Watts, L. (2016). Synchronous and asynchronous communication in distance learning: A review of the literature. Quarterly Review of Distance Education, 17(1), 23-32,56. Available at:

https://search.proquest.com/docview/1794526758?accoun tid $=6724$

White, C. (2003). Language Learning in Distance Education. Cambridge: Cambridge University Press.

https://doi.org/10.1017/CBO9780511667312

Zhang, S., \& Liu, Q. (2019). Investigating the relationships among teachers' motivational beliefs, motivational regulation, and their learning engagement in online professional learning communities. Computers \& Education, 134, 145-155.

https://doi.org/10.1016/j.compedu.2019.02.013 